\title{
Hearbal Detox Extract Formulation from Seven Wonderful Natural Herbs: Garlic, Ginger, Honey, Carrots, Aloe Vera, Dates, \& Corn
}

\section{Saleh Mohammed Yerima ${ }^{1 *}$, Chaturvedi Saurabh ${ }^{2}$, Bello Ibrahim ${ }^{3}$, Khan Mohammed Shahid2, Jain Harshita², Nama Nitin², Jain Vikas²}

\author{
${ }^{1}$ Disease Control Unit (Epidemiology), Yobe State Primary Health Care Management Board \\ (Ministry of Health) Yobe State, Nigeria \\ 2Department of Public Health, Faculty of Health Sciences, Career Point University Kota, \\ Rajasthan, India \\ ${ }^{3}$ National Biotechnology Development Agency, Abuja, Nigeria
}

\begin{abstract}
A B S T R A C T
The current mode of treatment of various diseases that cause as result of tobacco products based on synthetic drugs is very expensive, insalubrious and also not obtainable to all patients, at the same time these drugs alters genetics and metabolic pathways and also shows great adverse side effects to many patients. Hence, a safe and effective alternative natural remedy is needed to prevent the disease development and progression. In this lookout, natural recipes are indeed healthy and good remedy in the treatment/management of diseases that cause as result of tobacco products and these natural herbs are affordable, accessible and effective without any adverse side effects. These seven wonderful natural recipes (Garlic, ginger, honey, carrots, aloe Vera, dates \& corn) are considered to be the most significant ancient herbs that have been used as an herbal remedy for over 2500 years all over the world. Although this research is first of its kind, because there was no such research conducted by any researcher who combined these seven wonderful natural recipes as a therapeutics, however there were several similar earlier studies on one or combination of either these recipes which have shown a very remarkable and suitable alternative remedy in various diseases cure without any side effects. This juice extracts from seven wonderful natural recipes are of paramount important with an immense medical properties and health beneficial effects that treats cancer further complications, cleanse the nicotine $\&$ tar from lungs that cause as a result of tobacco uses, boost immune system, as well as serve as an antibiotic in the remedy of many ailments.
\end{abstract}

Keywords: Tobacco, cancer, 7 natural herbal formula- anti-cancer, anti-oxidant, anti-inflammatory

A R T I C L E I N F 0: Received 12 Feb 2019; Review Completed 20 April 2019; Accepted 10 May 2019; Available online 15 June 2019

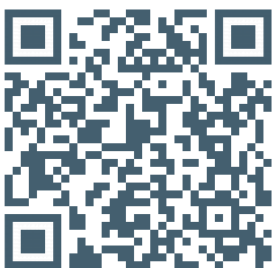

Cite this article as:

Saleh M Y, Chaturvedi S, Bello I, Khan M S, Jain H, Nama N, Jain V, Hearbal Detox Extract Formulation from Seven Wonderful Natural Herbs: Garlic, Ginger, Honey, Carrots, Aloe Vera, Dates, \& Corn, Asian Journal of Pharmaceutical Research and Development. 2019; 7(3):22-30, D0I: http://dx.doi.org/10.22270/ajprd.v7i3.485

*Address for Correspondence:

Mohammed Yerima Saleh, Disease Control Unit (Epidemiology), Yobe State Primary Health Care Management Board (Ministry of Health) Yobe State, Nigeria

\section{INTRODUCTION}

$\mathrm{T}$ obacco plant is native to North and South America continents and they knew it cultivation over 8000 years ago. It was Christopher Columbus who landed in America brought this plant to European countries. Portuguese traders brought tobacco plants to India during 1600 through Goa and Indians started cultivating it. Thus, the tobacco use spread from Americas to the rest of the world. In India, earlier it was restricted to Royal people but later in 17 th century even common people started using it. Gradually tobacco got assimilated in to cultural rituals and social fabric due to presumed medicinal and actually addictive properties attributed to it. Tobacco can be consumed in different forms and by different methods across the globe; in form of smoking, chewing, dipping or sniffing. In 2006, more than 1 billion smokers in the world consumed about 5.7 trillion cigarettes ${ }^{1,2}$. An additional 700 billion bidis are consumed annually in India alone3. There is wide variation in smoking prevalence among both males and females from one region to another. Globally, the prevalence of smoking is higher for men (40\% in 2006) than for women (nearly $9 \%$ in 20006), and males account $80 \%$ of all smokers (nearly 
1 billion). Tobacco use is the leading preventable cause of disease and death in the world. Worldwide, tobacco use accounts for more than six million death (5.4 million deaths due tobacco use and 0.6 million due to secondhand smoke) each year and is expected to cause more than eight million deaths by the year 20304 .

Tobacco consumptions has fallen substantially over the past 30 years in many industrialized countries as a result of the hazards of tobacco use and the implementation of aggressive and effective tobacco control policies. In contrast, over the same period, tobacco consumption has been increasing in the developing world; developing nations now consume the greatest share of the world's cigarette production1. Just as global tobacco consumption is shifting between the industrialized and developing countries; one of the saddest thing is, the tobacco pandemic is also spreading to women in a variety of settings. Historically, smoking by women in industrialized countries increased during the last century, lagging behind the rise in men by about 20 to 30 years ${ }^{5}$. This rise among women can be attributed to weakening social, cultural, and political constraints coupled with women's earning power and targeted marketing tobacco companies ${ }^{6}$.

\section{Health Benefits of each Ingredients Based on Scientific Evidence as follows}

\section{GINGER (Zingiber officinale Roscoe)}

The ginger belongs to the family of Zingiberaceaeand it is one of the most commonly consumed dietary condiments in the world ${ }^{7}$. Ginger originated in South-East Asia and then used in many countries as a spice and condiment to add flavor to food ${ }^{\mathbf{8}}$. Besides this, the rhizome of ginger has also been used in traditional herbal medicine. The health promoting prospective of ginger is attributed to its rich phytochemistry ${ }^{9}$. Ginger has staring potential for treating a number of ailments including degenerative disorders (arthritis and rheumatism), digestive health (indigestion, constipation and ulcer), cardiovascular disorders (atherosclerosis and hypertension), vomiting, diabetes mellitus, and cancer. It also has antiinflammatory and anti-oxidative properties for controlling the process of aging. Furthermore, it has antimicrobial potential as well which can help in treating infectious diseases and generation of free radicals or reactive oxygen species (ROS) during metabolism beyond the antioxidant capacity of a biological systems results in oxidative stress, which plays an essential role in heart diseases, cancer, and in the aging process. The bioactive molecules of ginger like gingerols have shown antioxidant activity in various modules ${ }^{9,10}$.

\section{HEALTH BENEFITS OF GINGER:}

\section{Anti-cancer Effects of Ginger}

The mechanism of ginger for acting as chemopreventive spice remains a matter of conflict among researchers. Ingredients like (6)-gingerol, (6)-shogaol, (6)-paradol, and zerumbone in ginger exhibits anti-inflammatory and antitumorigenic activities ${ }^{11,12}$. Ginger and its bioactive molecules are effective in controlling the extent of colorectal, gastric, ovarian, liver, skin, breast, and prostate cancers 11,13

\section{Anti-oxidative Stress Effects of Ginger}

The rich phytochemistry of ginger includes components that scavenge free radicals produced in biological systems. For the purpose of energy production, some free radicals which generated during the process of oxidation are essentials. In such circumstances of imbalance, extra antioxidant supplementation through dietary modules is essential for organism vitality, and the anti-oxidative properties of ginger and its components have been explored in various in vitro and in vivo tests. Strengthening the body's defenses by improving the antioxidant status will undoubtedly protect human against many chronic diseases ${ }^{9}$. 6-shogaol has exhibited the most potent antioxidant and anti-inflammatory properties in ginger, which can be attributed to the presence of alpha, beta-unsaturated ketone moiety ${ }^{\mathbf{1 4}}$.

\section{Anti-diabetic Effects of Ginger}

Some research studies have proved the effectiveness of ginger against diabetes and its complications. Weidner and Sigwart conducted an experimental study and indicated that ginger extract with a high content of gingerols and shogaols did not induce significant changes in blood glucose, blood coagulation, blood pressure, and heart rate in rat models ${ }^{\mathbf{1 5}}$. However, ginger significantly lowered blood pressure, serum total cholesterol, LDL, VLDL and triglycerides, and raised HDL in hyperglycemic rats, in models that are diabetic, deficient in the apolipoprotein $\mathrm{E}$ gene or those that have been fed a high lipid diet ${ }^{16}$.

\section{Anti-inflammatory Effects of Ginger}

In an ancient culture, medical practitioners focused on herbs for promoting the immune systems of body. In many countries ginger and its products raise the immune system ${ }^{17}$. Habib et al. showed that ginger extract can reduce the elevated expression of NFkaB and TNF- $\alpha$ in rats with liver cancer ${ }^{18}$.

\section{DATE PALM (phoenix dactylifera)}

Date palm (Phoenix dactylifera L.) is widely grown in the hot arid regions mainly in the Middle East and North Africa, and provides nutrition, as a staple food for centuries, food security, and raw material to the food industry. Every part of the date palm is useful. Dates offer useful prospects for fighting hunger and diseases. It is considered as a tree of life and sometimes as "Bread of Desert". This fruit was highly esteemed by the ancient civilizations more than 5000 years ago.Date, the fruit of date palm, can be considered as an ideal food that provides a wide range of essential nutrients with many potential health benefits. Eating dates in moderation can contribute immensely to health benefits, such as protecting against damage to cells from free radicals, helping preventing a stroke, coronary heart diseases and 
the development of colon, prostate, breast, endometrial, lung, and pancreatic cancers ${ }^{17-18}$.

\section{Medicinal Benefits of Date Palm (Phoenix Dactylifera)}

The benefits of dates include relief from constipation, intestinal disorders, heart problems, anemia, sexual dysfunctions, diarrhea, abdominal cancer, and many other conditions. Dates also help for a healthy weight gain. They are rich in several vitamins, minerals, and fiber.

\section{Antioxidant, Anti-inflammatory, Antimutagenic, and Anticancer Activities of Date Fruit}

In addition to their significance as an ideal high-energy food, in the folklore, the dates are believed to have many medicinal properties such as to provide strength, fitness, and relief against a number of ailments and pains including fever, stomach disorders, memory disturbances, nervous disorders, as well as aphrodisiac and to boost the immunity. They are also considered to protect against many chronic diseases including cancer and heart diseases 19. As they have been shown to contain antioxidant and antimutagenic properties ${ }^{20-21}$.

Aqueous extracts of dates have also been shown to inhibit the lipid peroxidation and protein oxidation as well as exhibit a potent superoxide and hydroxyl radical scavenging activity ${ }^{22}$. Panahi and Asadi (2009) reported that extract of date fruit were useful in controlling the blood cholesterol levels and also protected the CA1 neurons against oxidative injury ${ }^{23}$. Methanolic and aqueous extracts of date flesh and seeds have also been shown to exhibit anti-inflammatory properties and suppressed the swelling in the foot and adjuvant arthritis 24.

Dates are a rich source of hydroxyl pope folic acid and therefore eating on dates can increase the body's immunity and resistance to cancers. The preparations made from the extracted polysaccharides (glucans) from Lybian dates exhibited a dose-dependent anticancer activity by suppressing the growth of Sarcoma 180 tumor cells in female CD1 mice ${ }^{25}$. It is a common belief in the Middle East that the consumption of dates, particularly in the morning on an empty stomach, can reverse the actions of any toxic material that the subject may have been exposed to ${ }^{26}$.

\section{HONEY (Apis mellifera)}

Honey is an old ancient's medicinal use all over the world. The honey bee is believed to have originated in the Southern Asia, although some scholars say Africa. About 12,000 varieties of bees exist in the world. One of the earliest evidence of honey harvesting is on a rock painting dating back 8000 years; this one found in Valencia, Spain shows a honey seeker robbing a wide bee colony Honey helps to heal the stomach, pancreas and lungs as it tonifies, soothes and nourishes the linings of these organs. Even though honey is a sugar, it is loaded with nutrients, enzymes and minerals and therefore providing more benefits than just a sweet flavor.

\section{HEALTH BENEFITS OF HONEY}

\section{Anti-inflammation Action of Honey}

Honey reduces the activity of cytooxygenase- 1 and cyclooxygenase- 2 , thus showing anti-inflammatory effects and demonstrates immunomodulatory activities, and furthermore, ingestion of diluted natural honey showed reduction effect on concentrations of prostaglandins such as prostaglandin $\mathrm{F} 2$, prostaglandin $\mathrm{F} 2 \alpha$, and thromboxane B2 in plasma of normal individuals ${ }^{27}$. Bilsel et al. (2002) have proved that anti-inflammatory activity of honey was as effective as prednisolone, reference drug ${ }^{28}$. Furthermore, honey has an anti-inflammatory action free from adverse side effects, such as suppression of immune response and tissue growth, formation of ulcers in stomach, etc ${ }^{27,28}$.

\section{Anti-oxidants Activity of Honey}

Honey has exhibited a strong antioxidant potential and its activity is strongly correlated with the content of total phenolics, and the color of honey. It was found that dark honey has higher total phenolics content than the other, and consequently, a higher antioxidant capacity honey also has an exhibited oxidative stress which may be partly responsible for its neuroprotective activity. Hyperlipidemia and production of free radicals are risk factors for cardiovascular diseases, a wide range of phenolics compounds are present in honey which has promising effect in the treatment of cardiovascular diseases $29-30$

\section{Anti-diabetic Properties of Honey}

The use of honey in Type I and II diabetes was associated with significantly lower of glycemic index than with glucose or sucrose in normal diabetes. Due to the low glycemic index of the honey, it helps to reduce the absorption of digested food. Honey compared with dextrose caused a significantly lower rise in plasma glucose levels in diabetic subjects. It also caused reduction of blood lipids, homocysteine levels and Creactive protein levels in normal and hyperlipidemic subjects ${ }^{30,31}$

\section{Antimicrobial Activity of Honey}

Honey has been reported to have antibacterial activity against various bacterial species including Bacillus anthracis, Corynebacterium diphtheria, Haemophilus influenzae, Klebsiella pneumoniae, Listeria monocytogenes, Mycobacterium tuberculosis, Pasteurella multocida, Yersinia enterocolitica, Proteus species, Pseudomonas aeruginosa, Acinetobacter species, Salmonella diarrhea, Salmonella typhi, Serratia marcescens, Shigella dysentery, Staphylococcus aureus, streptococcus faecalis, Streptococcus mutans, Streptococcus pneumoniae, Streptococcus pyogenes, and Vibrio cholera ${ }^{31,33-34}$. 


\section{Wound Healing Activity of Honey}

Honey has cleansing action on wound, stimulates tissue regeneration, reduces inflammation, and honey impregnated pads act as non-adhesive tissue dressing, clinical trials have revealed that honey dressing showed better improvement (e.g., dressing in burns with amniotic membrane dressing; silver sulfadiazine dressing, and boiled potato peel dressing) and showed early healing with lesser degree of contracture and scarring ${ }^{31}$.

\section{GARLIC (Allium sativum Linn.)}

Garlic or Allium sativum Linn (Alliaceae), originally indigenous to Asia, ancient civilizations used garlic to treat asthma, digestive disorders, heart diseases, infections, respiratory disorders, tumors, and even intestinal worms. Today, science claims for the health benefits of garlic include lower blood pressure and cholesterol, an anti-inflammatory effect, reduced risk of cancer, and a stronger immune system. Scientific research has revealed that garlic or its constituents indeed have a broad range of biological activities including immune stimulation, anticarcinogenic and antitumour activity besides being natural antibiotics with antiviral, antibacterial and antifungal actions. In recent times effects of garlic on cardiovascular diseases have been much publicized ${ }^{35-37}$.

\section{Garlic and Anticarcinogenesis}

Several experimental studies on animals and cultured cells have demonstrated the anticarcinogenic effect of garlic and its chemical compounds. Oral feeding of garlic extracts has been shown to reduce the incidence and growth of transplantable and spontaneous tumours in experimental animals and the active components were found to influence a number of physiological and immunological functions which account for their anticarcinogenic and antitumour effects. When garlic oil was topically applied during the initiation phase of benzo (a) pyrene (BP) induced skin carcinogenesis in mice, a decline was noted in the incidence and multiplicity of tumours ${ }^{35}$. Oral administration of fresh water extract of garlic was shown to result in reduction of chemically induced cervical carcinomas in mice ${ }^{36}$. Garlic treatment inhibited development of murine transitional cell carcinomas significantly, and an aqueous extract effectively suppressed dimethylbenz(a)anthracene (DMBA) induced oral carcinogenesis in hamsters by modulation of lipid peroxidation and glutathione (GSH), glutathione-stransferase (GST) and glutathione peroxidase (GPx) levels ${ }^{37}$.

Experimental investigations have implicated specific thioallyl constituents and their derivatives regarding the anti-cancer actions of garlic, although many other cancer chemopreventive compounds are also known to be present. The efficacy of various garlic derived compounds in inhibiting experimental carcinogenesis has been investigated by many ${ }^{35-37}$.

\section{HEALTH BENEFITS OF GARLIC}

- Garlic is nutrient dense: high in the good stuff like manganese, vitamins B6 and C, selenium, and fiber your body needs without heavy calories. It even has a bit of protein and carbs.

- Garlic is a power antioxidant: free radical damage that leads to body-wide inflammation is the root cause of many diseases and conditions including heart disease, obesity, diabetes, aging, Alzheimer's, and cancer. Garlic "ramps up" your body's ability to fight free radicals. If you suffer from an autoimmune disease (a growing epidemic around the globe), you need garlic in your daily diet!

- Garlic is an excellent for your heart: researchers in Saudi Arabia found that the equivalent of four cloves of garlic was effective as a hypertension drug called "Atenolol". Red blood cells convert the sulfuric compounds of garlic into hydrogen sulfide gas, which helps to expand blood vessels and lower pressure. Garlic also lowers LDL "bad" cholesterol by much as $15 \%$ overall and has been proven to help prevent hardening of the arteries (atherosclerosis).

- Garlic boosts your immune system: one study conducted during prime cold season in the United Kingdom found that participants using garlic had $60 \%$ fewer colds that wrapped up faster (with less extreme symptoms) than those on a placebo. Steeping crushed garlic in tea (with a bit of lemon and honey) could be the cold relief you have been looking for all your life.

- Garlic is effective against fungus and parasites: Regular consumption of garlic can help prevent negative effects of bacteria and parasites in your food (including food poisoning). Studies have included using fresh garlic to treat E. Coli, Staphylococcus aureus, and salmonella enteritis. Also, for those who suffer from athlete's foot. Adding garlic to your eating plan is an excellent way to get rid of many health problems.

- Garlic is a natural (and highly effective) detoxifier: Not only is garlic excellent at mopping up free radicals and heavy metals in the blood. One study found that lead in the body of men who worked in a battery factory went down by $19 \%$ using garlic.

- Garlic is great for your skin: The sulfuric compounds in garlic are excellent against inflammatory conditions of the skin such as psoriasis, eczema, and acne, ${ }^{35-37}$.

\section{ALOE VERA}

Aloe Vera has a number of synonyms: (Aloe barbadenis Mill, Aloe indica Royle,Aloe perfolista L. var, and Aloe Vulharis Lam.). The species epithet vera means "true" or 'genuine'. Aloe vera has been used for medicinal purposes in several cultures for millennia: Greece, Egypt, India, Mexico, Japan, and China and other part of the world. The Egyptians used the Aloe vera to make papyrus like scrolls as well as for the treatment of tuberculosis and many other ailments.

The bioactive compound of Aloe vera are used as astringent, haemostatic, antidiabetic, antiulcer, antiseptic, antibacterial, anti-inflammatory, antioxidant, and anticancer agents, also very effective in treating stomach ailments, gastrointestinal problems, skin diseases, constipation, radiation injury, dysentery and diarrhoea as well as wound and burn healings. Aloe leaves can be 
separated into two basic products: the latex, a bitter yellow liquid beneath the epidermis of the leaf and the gel, a colourless and tasteless substance in the inner part of the leaf. Both of them have many biologically active components, mainly anthraquinones and polysaccharides (the most active is acemannan), which may act alone or in synergy. Aloe Vera seems to treat a variety of conditions because of it wounds healing, anti-inflammatory, immunity, antidiabetic, antioxidant, laxative, antibacterial, antifungal, antiviral, and antitumor effects.

The effect of Aloe vera L. in rat lungs after cigarette smoke induction has shown the great negative effects of smoking. The incident of smoking is one of the world's health problems, as smoking increases the incidence of chronic obstructive pulmonary disease (COPD). Aloe vera $\mathrm{L}$ has anti-inflammatory, immunomodulator, and $\beta$ sitosterol properties ${ }^{38}$.

\section{HEALTH BENEFITS OF ALOE VERA}

Anti Cancer Effects of Aloe-vera: the role of Aloe vera in carcinogenicity has not been evaluated well. The chronic abuse of anthranoid containing laxatives has been hyphotised to play a role in colorectal cancer, however, no causal relationship between anthranoids laxative abuse and colorectal cancer has been demonstrated 39, and report on cancer prevention has shown that Aloe vera juice enables the body to heal itself from cancer and also from the damage of caused by radio and chemotherapy that destroys healthy immune cells crucial for the recovery ${ }^{40}$.

Anti-inflammatory Action of Aloe-vera: The Aloe sterol includes campesterol, $\beta$-sitosterol, lupeol, and cholesterol which are anti-inflammatory in nature, helps in reducing the inflammation pain and act as a natural analgesic. Other aspirin like compound present in Aloe is responsible for anti-inflammatory and antimicrobial properties $^{41}$.

Antidiabetic Effects of Aloe-vera: The five phytotesterols of Aloe vera, i.e; lophenol, 24-metthyllophhenol, 24-ethyl-lophenol, cycloartanol and 24methyl-lenecycloartanol showed anti-diabetic effects in type- 2 diabetic mice ${ }^{42}$.

Aloe-vera Effects on the Immune System: Alprogen inhibit calcium influx into mast cells, thereby inhibiting the antigen-antibody-mediated release of histamine and leukotriene from mast cells ${ }^{42,43}$.

Antitumor Activity of Aloe-vera: A number of glycoproteins present in Aloe vera gel have been reported to have antitumor and antiulcer effects and increase proliferation of normal human dermal cells. In recent studies, a polysaccharide fraction has shown to inhibit the binding of benzopyrene to primary rat hepatocytes, thereby preventing the formation of potentially cancerinitiating benzopyrene-DNA adducts. An induction of glutathione S-transferase and an inhibition of the tumor promoting effects of phorbol myristic acetate has also been reported which suggest a possible benefit of using aloe gel in cancer chemoprevention ${ }^{44}$.

Laxative Effects of Aloe-vera: Anthraquinones present in latex are a potent laxative; it is stimulating mucus secretion, increase intestinal water content and intestinal peristalsis, and Aloe latex is known for its laxatives properties. The laxative effect of Aloe is not generally observed before 6 hours after oral administration, and sometimes not until 24 or more hours after ${ }^{45}$.

Antiseptic Effects of Aloe-vera: The antiseptic property of Aloe vera is due to presence of six antiseptic agents' namely-lupeol, salicylic acid, urea nitrogen, cinnamonic acid, phenols and sulphur. These compounds have inhibitory action on fungi, bacteria, and viruses. Although most of these uses interesting controlled trials are essential to determine its effectiveness in all diseases ${ }^{46}$.

Stress Effects of Aloe-vera: Aloe juice is helpful in smooth functioning of the body machinery 47 . It reduces cell-damaging process during stress condition and minimizes biochemical and physiological changes in the body, and Oxidative stress refers to chemical reactions in which compounds have their oxidative state changed. Some antioxidants are part of the body's natural regulating machinery while other dietary antioxidants are derived from diet sources. Aloe vera is an excellent example of a functional food that plays a significant role in protection from oxidatives stress ${ }^{48}$.

Wound Healing Effects of Aloe-vera: Acemannan is the main functional component of aloe vera, is composed of a long chain of acetylated mannose. This complex carbohydrate accelerate wound healing and reduces radiation induced skin reactions 45,49 . Macrophageactivating potential acemannan may stimulate the release of fibrogenic cytokines 45. Direct binding of acemannan to growth factors and their stabilization may lead to promotion of prolong stimulation of granulation ${ }^{49}$.

\section{CARROT (Daucus carota $\mathbf{L}$.)}

Carrot (Daucus carato L.) is the family of most important crop of Apiaceae family. It is a root vegetable that has worldwide distribution. Carrots were first used for medical purposes and gradually used as food. Written records in Europe indicated that carrots were cultivated prior to the tenth century. The colors of the carrots root flesh may be white, yellow, orange, red, purple, or very dark purple. The first cultivated carrots were yellow and purple fleshed cultivars. Orange carrots, today more popular, were developed in the 15 th and 16th centuries in central Europe. A rapid rise in the popularity of orange carrots was observed with the recognition of its high 
provitamin 'A' contents 50, 51. Carotenoids and anthocyanins are the major antioxidant pigments found in carrots. Cultivar differences in carrots rely in the type of pigments present. Carotenoids are the yellow, orange, or red colored phytochemicals found in most yellow and orange fleshed cultivars. The widely used of orange carrot is high in $\alpha$-and $\beta$-carotene and is a rich source of provitamin ' $A$ '. Yellow carrot color is due to lutein which plays an important role in prevention of macular degeneration ${ }^{51}$.

Carrot is a good source of dietary fiber and of the trace mineral molybdenum, rarely found in many vegetables. Molybdenum aids in metabolism of fats and carbohydrates and important for absorption of iron. It is also good source of magnesium and manganese. Magnesium is needed for bone, protein, making new cells, activating $\mathrm{B}$ vitamins, relaxing nerves and muscles, clothing blood, and in energy production. Insulin secretion and function also require magnesium. Manganese is helpful in carbohydrate metabolism, in coordination with enzymes in the body ${ }^{51,52}$.

\section{HEALTH BENEFITS OF CARROT}

Antioxidants, Anticarcinogen, and Immunoenhencer Benefits of Carrot

Like many other colored vegetables carrot is a gold mine of antioxidants. Carotenoids, polyphones and vitamins present in carrot act as antioxidants, anticarcinogens, and immunoenhencers. Carotenoids widely distributed in orange carrots are potent antioxidants which can neutralize the effect of free radicals. They have been shown to have inhibition mutagenesis activity contributing to decrease risk of some cancers ${ }^{51,52}$. Zhang and Hamauzuet ${ }^{51-55}$ reported that flavonoids and phenolics derivates, present in carrot roots play also an important role as antioxidants. They also exert anticarcinogenic activities, reduce inflammatory insult, and modulate immune response $(\mathbf{5 1}, \mathbf{5 2})$.

The study suggests that the aliphatic C17-polyacetylenes are the potential anti-cancer principles of carrots and that the synergistic interaction between bioactive polyacetylenes may be important for their bioactivity. Other studies have reported that falcarinol exerts cytotoxic activity of against several human tumor cell lines in vitro, destroying pre-cancerous cells in the tumors ${ }^{53,54}$.

Besides cart loads of $\beta$-carotene and other carotenoids, carrots contain vitamins such as vitamin $\mathrm{C}$ and $\mathrm{K}$, thiamin (B1), riboflavin (B2), pyridoxine (B6) and folates (B9), necessary for metabolism of carbohydrates, proteins and healthy growth ${ }^{51,52}$. Vitamin $\mathrm{C}$ promotes the absorption of non-heme iron and is required for fighting infections and vitamin $\mathrm{K}$ helps in preventing bleeding. Thiamin (B1) has highly beneficial effects on our nervous system and mental attitude; riboflavin is necessary for cell respiration, and red blood cell formation; pyridoxine inhibits the formation of homocysteine and reduces the risk of heart diseases; and folates may also reduce the risk of heart attack by lowering homocysteine levels. High level of homocysteine has been found to be associated with an increased risk of hardening of arteries due to the accumulation of fatty plaques. It also protects against birth defects in babies ${ }^{51,52}$.

Antidiabetic, Anti-Hypertensive Cholesterol and Cardiovascular Diseases Lowering Benefits of Carrots Nutritionals generally recommend eating carrots in moderation because they contain more sugar than any other vegetables. This recommendations was based on the first journal articles ever published on the carrot glycemic index (GI), in 1981, indicated that we quickly digest the carbohydrates in carrots. That study showed the carrots had GI of 92 (where glucose=100). A later study that got much less attention showed the carrots had a GI of $39 \pm 7$ and the carrot juice of $45 \pm 4$ (Cale not pub). Recent research demonstrates a significant association between vitamin A rich carotenoids and diabetes status. According to these investigators higher blood glucose levels, as well as higher fasting levels of insulin, were observed in study participants with lower level of carotenoids. Carotenoid levels also decreased as the severity of glucose intolerance increased. These findings suggest that carrot and vitamin A rich carotenoids might help diabetics to manage their condition $^{55}$.

Nicolle et al. ${ }^{56}$, reported that carrot showed cholesterol absorption mitigating effects in experimental carrot fed rats. Regulation in bile acid secretion and antioxidant status was also observed by these investigators. Moreover, carrot consumption increased the vitamin $\mathrm{E}$ level in plasma and increased the ferric reducing ability of plasma, and the consumption of carrots also been associated with lower risk of heart attacks in women ${ }^{56}$.

\section{Hepatoprotective and Renoprotective Benefits of} Carrot

Bishayee et al. ${ }^{57}$, observed that carrot extract help to protect liver from acute injury by the toxic effects of environmental chemicals. In its study of carrot extract on carbon tetrachloride (CC14) induced acute liver damage in mouse was evaluated. The increase serum enzymes levels by CC14-induction were significantly lowered due to the pre-treatment with carrot extract. Seed extracts and its essential oil have been reported in experimental studies to have cardio- and hepato-protective, cognitive dysfunction, cholesterol lowering, anti-bacterial, antifungal, anti-inflammatory, analgesic, and wound healing benefits ${ }^{58}$.

\section{Skin Care Benefits of Carrots}

Nicotine damages skin and carrots contains large amounts of vitamins $\mathrm{A}, \mathrm{K}, \mathrm{C}$, and $\mathrm{B}$ all these vitamins are proven to efficiently remove nicotine in the body. Carrot juice is also great when it comes to lung health, and protecting the respiratory system from infections. It can help counter the bad effects that are associated with smoking. Furthermore carrot juice is rich of vitamins that can help greatly reduce the risk of emphysema. Studies suggest eating a few carrots per day could actually cut the rate of lung cancer in half. Researchers believe this is due to the levels of gamma-carotene, lycopene, lutein xanthophylls, and alpha-carotene ${ }^{57,58}$.

\section{MAIZE OR CORN (ZEA MAYS L.)}

Maize or corn (Zea Mays L.) is the world's third leading cereal crop, after wheat and rice. It is probably originated from America, specifically Mexico. Maize belongs to 
family of poaceae and is a tall annual herb with extensive fibrous root system. The word Zea mays derives from two languages. Zea come from ancient Greek and is a generic name for cereal and grains. Some scientists believe that Zea stands for "sustaining life" while Mays comes from the language Taino, meaning 'life giver'.

\section{HEALTH BENEFITS OF MAIZE:}

The composition of maize endows it with many health benefits. The high fiber content of maize prevents constipation and colorectal cancer. Antioxidants neutralize the effects of harmful free radicals that cause disease like cancer. The antioxidant beta cryptoxanthin prevents lung cancer, while lutein prevents age related vision loss. Antioxidants slow cognitive decline and conditions like Alzheimer's. Vitamin $\mathrm{C}$ boosts immunity and fights infection, while the presence of vitamin $\mathrm{E}$ gives maize anti-aging properties. In the traditional system of medicine, maize is found to be effective as an analgesic, astringent, anti-allergic, anti-lithiasis, anti- hypertensive, against skin rashes, anti-angina, anti-prostatitis, antitumor, anti-dysentery, anti-diarrheal, against skin rashes, against Biliousness, against sore throat, also use an a emollient as well as urinary disorders including dysuria, Cystitis, Urethritis, Nocturnal enuresis ${ }^{59}$.

\section{Anti-oxidant Activity of Maize}

Corn silk was extracted to prepare five fractions viz. ethanol extract, petroleum ether fraction, acetic ether fraction, nbutanol fraction and water fraction. The butanolic fraction exhibited the highest antioxidant and free radical scavenging activity. The two flavone glycosides isolated from butanolic fraction viz., isoorientin-2"-O- $\alpha$-L-rhamnoside and 3"-methoxymaysin, were also found to possess potent antioxidant moieties (60, 61). Ethanolic extract of the Egyptian corn silk reflected profound free radical scavenging activity, and CS ethanol extract inhibited $\gamma$-radiation-induced damage in liver, reduced the MDA content in a dose-dependent manner and safeguarded the liver from GSH depletion ${ }^{61}$.

\section{Anti-inflammatory Activity of Maize}

Corn silk ethanolic extract elicited significant TNF- $\alpha$ antagonistic activity. The extract efficiently abolished the TNF- $\alpha$ and LPS-induced adhesiveness of EAhy 926 endothelial cells to monocytic U937 cells. Corn silk possesses important therapeutic potential for TNF- $\alpha$ and LPS-mediated leukocyte adhesion and trafficking ${ }^{62}$. CS extract diminished cell migration, exudate formation, oxidative stress, TNF- $\alpha$, IL-1 $\beta$, VEGF- $\alpha$, and IL-17A and blocked inflammation-related events (ICAM-1 and iNOS), illustrating its anti-inflammatory effect ${ }^{63}$.

\section{Anti-fatigue Activity of Maize}

Corn silk flavonoids raised swimming time in mice, accompanying diminished levels of blood lactate, blood urea nitrogen (BUN) and elevated hepatic glycogen concentration. These results manifested anti-fatigue and enhanced exercise tolerance property of corn silk ${ }^{64}$.

\section{Nephrotoxicity Reduction Activity of Maize}

CS administration dose dependently prevented GMinduced interstitial nephritis and reduced serum creatinine level ${ }^{65}$.

\section{MATERIALS AND METHODOLOGY}
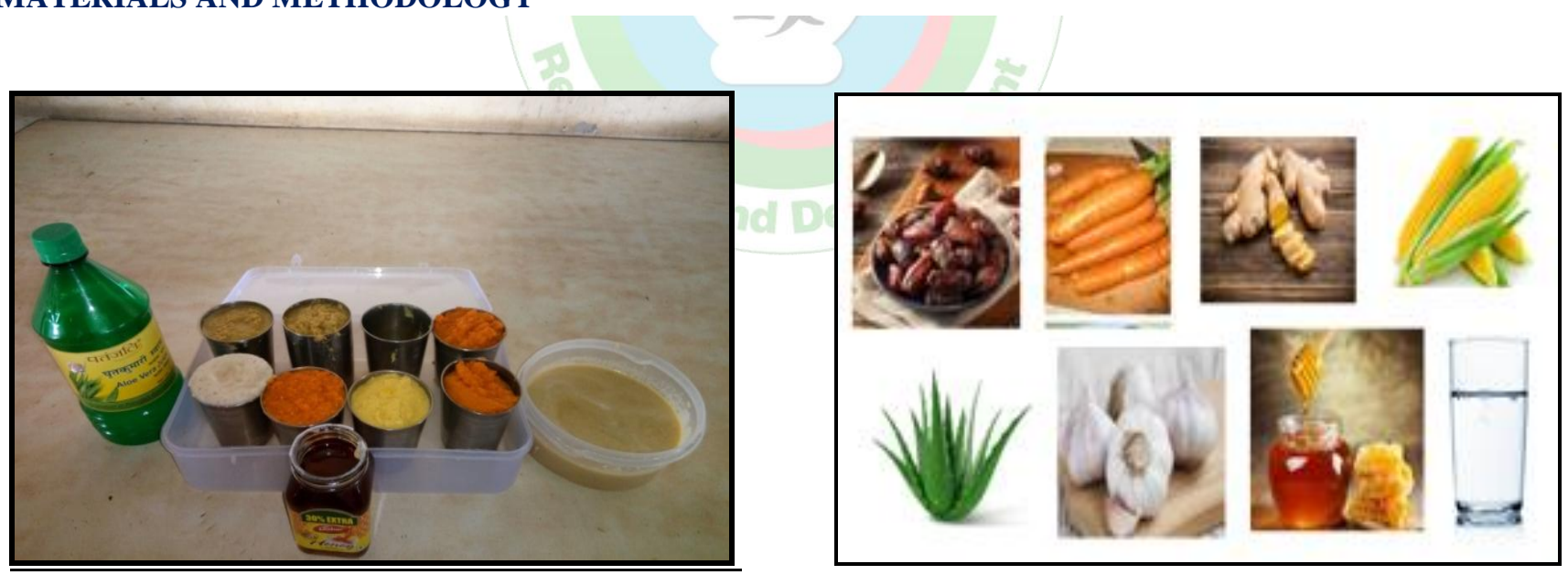

Table 1: Ingredients of Extract

\begin{tabular}{|l|l|l|}
\hline S.No & Ingredients & Quantities $\mathbf{( 2 5 0} \mathbf{~ m l})$ \\
\hline 1. & Ginger & $20 \mathrm{ml}$ \\
\hline 2. & Garlic & $15 \mathrm{ml}$ \\
\hline 3. & Dates Palm & $35 \mathrm{ml}$ \\
\hline 4. & Carrot & $25 \mathrm{ml}$ \\
\hline 5. & Corns & $30 \mathrm{ml}$ \\
\hline 6 & Aloe Vera & $15 \mathrm{ml}$ \\
\hline 7. & Honey & $25 \mathrm{ml}$ \\
\hline 8. & Water & $85 \mathrm{ml}$ \\
\hline & Total & $250 \mathrm{ml}$ \\
\hline
\end{tabular}




\section{METHOD OF PREPARATION}

- Wash all the ingredients thoroughly. Boil water, grate the ginger, carrot \& corns, and chop the garlic, date and squeeze the Aloe vera; mix \& blend them with blender, add to the boiling water.

- When it boils again, lower the heat and add the honey, next simmer the mixture until it is completely mixed. Finally, take the mixture off of the heat and strain it into a jar or container.

- Leave the remedy to cool \& then bottle them.

USES: Take two tablespoon of this natural remedy 2times in a day: one in the early morning on an empty stomach \& again after snack or dinner.

\section{DISCUSSION}

These seven wonderful natural recipes are considered to be the most significant ancient herbs that have been used as an herbal remedy for over 2500 years all over the world. Although this research is first of its kind, because there was no such research conducted by any researcher who combined these seven wonderful natural recipes as a therapeutic, however there were several similar earlier studies on one or combination of either these recipes which have shown a very remarkable and suitable alternative remedy in various disease cure without any side effects and hence urging for further pharmacological investigation plus clarification of this formula to prove it.

\section{CONCLUSION}

This formula that extracted from well known 7 wonderful natural herbs has a very significance role to soothe human life in a myriad ways. Pharmacological and nutritional studies have greatly shown the remarkable medicinal properties of these herbs-such as anticancer, anti-oxidant, anti-inflammatory, antibiotic, antifungal, antibacterial, antiviral, antiseptic, disinfectant, immunomodulator, detoxifier, etc. and therefore this formula (combined extract juice) of Garlic, Ginger, Honey, Carrots, Aloe Vera, Dates \& Corn is an effective remedy of many ailments, not only nicotine and tar cleanser. In this lookout, natural recipes are healthy and good remedy in the treatment/management of diseases that cause as result of tobacco products based on assorted scientific research findings and these natural herbs are affordable, accessible and effective without any adverse side effects.

\section{FUTURE PROSPECTIVE:}

This juice extracts from seven wonderful natural recipes is of paramount important with an immense medical properties and health beneficial effects that treats cancer's further complications, cleanse the nicotine $\&$ tar from lungs that causes as a result of tobacco uses, boost immune system, as well as serve as an antibiotic in the remedy of many ailments. Many smokers want to quit smoking but due maintenance of tobacco use results from nicotine addiction make them difficult in quitting tobacco abuses and therefore this herbal formula offers way to remove that built-up Nicotine \& Tar and will play a tremendous roles on reducing high death rate as a result of tobacco. Smokers and those who intended to quit smoking as well as those who have already quit smoking should be aware of the fact that their lungs are full of Nicotine \& Tar. Ideally, the best solution is to quit smoking and get remedy from this formula because nicotine seriously damages the lungs, and those dangerous effects are irreversible.

\section{ACKNOWLEDGMENT}

The author is thankful to departments of Public Health and of that Pharmacy, Career Point University, Kota for providing facility and guidance to carry out this scientific experiment and at the same time a special appreciations goes to Yobe State Government, Nigeria for their financial support.

\section{REFERENCES}

1. WHO report on the global tobacco epidemic (2009) "Implementing smoke free environments". Geneva,World Health organisation, 2009.

2. Shafey $\mathrm{O}$ et al. The tobacco atlas, 3rd ed". Atlanta, GA, American Cancer Society, 2019.

3. Asma S, Gupta PC. Bidi smoking and Public Health. Mumbai, India Ministry of Health. 2008.

4. Mathers et al.Updated Projections of Global Mortality and Burden of Disease. (2002-2030): Date Sources, Methods and Results. WHO2006.

5. Lopez AD, Collishaw NE, Piha T. "'A Descriptive Model of the Cigarette Epidemic in Industrialized Countries". Tobacco control, 1994; (3):242-247.

6. Harm reduction in nicotine addiction: Helping people who cannot people quit. A report by the Tobacco Advisory Group of the Royal College of physicians. London, Royal College of physicians, 2007.

7. Surh Y.J, Park K.K, Chun S, Lee L. J, Lee E, Lee S. S. Antitumor Promoting Activities of Selected Pungent Phenolic Substances Present in Ginger. J Environ Pathol Toxicol Oncol. 1999; 18(2):131139

8. Park EJ, Pizzuto JM. Botanicals in Cancer Chemoprevention. Cancer Metast Rev. 2002; (21):231-55.

9. Shukla Y., Singh M. Cancer Prevention Properties of Ginger: $A$ Brief Review. Food Chem Toxicol. 2007; (45):683-690.

10. NicollR, Henein MY. Ginger (Zingiber officinale Roscoe): A Hot Remedy of Cardiovascular Diseases. Int. J Cardiol. 2009; (131):408149.

11. Jeong CH Bode AM, Pugliese A, Cho YY, Kim HG, Shim JH. (6)gingerol Suppresses Colon Cancer Growth by Targeting Leukotriene a4 Hydrolase"'. Cancer Res. 2009; (69):5585-5591.

12. Hung JY, Hsu YL, Li CT, Ko YC, Ni WC, Huang MS, et al.(6)Shogaol, an Active Constituent of Dietary Ginger, Induces Autophagy by Inhibiting the AKT/mTOR Pathway in Human Nonsmall Cell Lung Cancer A549 Cells. J Agric Food Chem. 2009; (57):9809-9816.

13. Ishiguro K, Ando T, Maeda O, Ohmiya N, Niwa Y, Kadomatsu K, et al. Ginger Ingredients Reduce Viability of Gastric Cancer Cells via Distinct Mechanisms. Biochem Biophy Res Commun. 2007; (362):218-223.

14. Dugasani S, Pichika MR, Nadarajah VD, Balijepalli MK, Tandra S, Korlakunta JN. Comparative Antioxidant and Anti-inflammatory Effects of (6)-gingerol, (8)-gingerol, (10)-gingerol, and (6)-shogaol. J. Ehnopharmacol. 2010; (127):515-520.

15. Weidner MS, Sigwart K. 'The Safety of a Ginger Extract in the Rat. J Ethnopharmacol. 2000; (73):513-520.

16. Fuhrman B, Rosenblatt M, Hayek T, Coleman R, Aviram M. ' 'Ginger Extract Consumption Reduces Plasma Cholesterol, Inhibits LDL Oxidation and Attenuates Developments of Atherosclerosis in Atherosclerotic, Application E-deficient Mice. J Nutr. 2000; (130):1124-1231.

17. Barta I, Smerak P, Polivkova Z, Seskakova H, Langova M, Turek B, et al. Current Trends and Prospective in Nutrition and Cancer Prevention. Neoplasm. 2006; (53):19-25.

18. Habib SH, Makpol S, Abdul Hamid NA, das S, Ngah WZ, Yusof YA.Ginger Extract (Zingiber officinale) has Anti-cancer and Antiinflammatory Effects on Ethionine-induced Hepatoma Rats. Clinics (Sao Paulo). 2008; (63):807-813.

19. Lambiote, B. Some aspects of the role of dates in human nutrition: In Proceedings of the First International Symposium on Date Palm. King Faisal University, Saudi Arabia, 23-25 March, 1982, p.16.

20. Al-Farsi, M, Alasalvar, C., Morris, A., Baron, M., and Shahidi, F. b. Comparison of antioxidant activity, anthocyanins, carotenoids, and phenolic of three native fresh and sun dried date (Phoenix dactylifera L.) varieties grown in Oman. Journal of Agriculture and Food Chemistry. 2005; (53):7592-7599. 
21. Vayalil, PK, Antioxidant and antimutagenic properties of aqueous extract of date fruit (Phoenix dactylifera L. Arecaceae)', Journal of Agriculture and Food Chemistry. 2002; (50): 610-617(s).

22. Allaith, Abdull, AA, In-vitro evaluation of antioxidant activity of different extracts of Phoenix dactylifera L. fruit as functional foods'". Deutsche Lebensmittel Rundschau. 2005; (101): 305-308.

23. Panahi, A. and Asadi, M, 2009.Cholesterol lowering and protective effects of date fruit extracts: An in-vivo study. Toxicology Letters 189S: S57-S273 (F25).

24. Mohammed, D.A. and Al-Okbi, SY, 2004. In-vivo Evaluation of Antioxidant and Anti-inflammatory Activity of Different Extracts of Date fruits in Adjuvant Arthritis. Polish Journal of Food and Nutrition Science 2004; (13): 397-402.

25. Ishruda, O. and John, FK, The Anticancer Activity of Polysaccharide Prepared from Libyan Dates (Phoenix dactylifera L.). Carbohydrate Polymers. 2005; (59): 531-535(s).

26. Vyawahare, N, Pujari, R, Khsirsagar A, Ingawale, D, Partil M, and Kagathara V, Phoenix dactylifera: An update of its indigenous uses, phytochemistry and pharmacology. Internet Journal of Pharmacology. 2009; 7:1

27. Al-Waili NS, Boni NS, Natural Honey Lowers Plasma Prostaglandin Concentrations in Normal Individuals. J Med Food. 2003; (6): 129133

28. Bilsel Y, Bugra D, Yamaner S, Bulut T, Cevikbas U, Turkoglu U. Could Honey Have a Place in Colitis Therapy Effects of Honey, Prednisolone, and Disulfiram on Inflamma, NitricOxide, and Free radical Formation. Dig Surg. 2002: (19): 306-311.

29. Al-Mamary M, Al-Meeri A, Al-Habori M. Antioxidant Activities and Total Phenolics of Different Types of Honey. Nutr Res 2002; (22): 1041-1047.

30. Blasa M, Candiracci M, Accorsi A, Piacentini MP, Albertini MC, Piatti E. Raw Millefiori Honey is packed Full of Antioxidants. Food Chem. 2006; (97): 217-222.

31. Bansal V, Medhi B, Pandhi P. Honey-A Remedy Rediscovered and its therapeutics Utility. Kathmandu Univ Med J (KUMJ). 2005; (3) 305-309.

32. Al-waili NS. Natural Honey Lowers Plasma Glucose, C - reactive protein, Homocysteine, and Blood Lipids in Healthy, Diabetic, and Hyperlipidemic Subjects: Comparison with dextrose and Sucrose. J Med Food. 2004; (7):100-107

33. Jeffrey AE, Echazarreta CM. Medical Uses of Honey. Rev Biomed 1996; (7): 43-49

34. Asadi-Pooya AA, Pnjehshahin MR, Beheshti S. The Antimycobacterial Effect of Honey: An In vitro Study. Riv Biol 2003; (96):491-495.

35. Sadhana AS, Rao AR, Kucheria K, et al. Inhibitory Action of Garlic Oil on the Initiation of Benzo(a)pyrene-induced Skin Carcinogenesis in Mice. Cancer Lett. 1988; (40):193-7.

36. Hussain SP, Jannu LN, Rao AR, Chemopreventive Action of Garlic on Methylcholanthrene-induced Carcinogenesis in the Uterine Cervix of Mice. Cancer Lett. 1990; (49):175-80.

37. Balasenthil S, Arivazhagan S, Ramachandran CR, Effects of Garlic on Dimethylbenz (a) Anthracene Induced Hamster Buccal Pouch Carcinogenesis. Cancer Det Prev. 1999; (23):534-48.

38. Schramm DD, Karim M, Schrader HR, Holt RR, Cardetti M, Keen CL. Honey with High Levels of Antioxidants Can Provide Protection to Healthy Human Subjects. J Agric Food Chem. 2003; (51): 1732-1735.

39. Siegers CP, Anthranoid Laxatives and Colorectal Cancer, Trends in Pharmacological Sciences. 1992; 13:229-231.

40. Fenig E, Nordenberg J, Beery E, Sulkes J and Wasserman L, Combined Effect of Aloe-Emodin and Chemotherapeutic Agents on the Proliferation of an Ad-herent Variant Cell Line of Merkel Cell Carcinoma, Oncology Reports. 2004; 11(1):213-217.

41. www.healingaloe.com, Immunomodulatory Properties of Aloe vera Gel in Mice, International Journal of Green Pharmacy. 2008; 2(3):152-154

42. Tanaka M, et al., Identification of Five Phytosterols from Aloe vera Gel as Antidiabetic Compounds. Bio- logical and Pharmaceutical Bulletin. 2006; 29(7):1418-1422.

43. Hanley DC, WA. Solomon, B. Saffran and R. H. Davis, The Evaluation of Natural Substances in the Treatment of Adjuvant Arthritis, Journal of the American Podiatric Medical Association. $1982 ; 72: 275-284$
44. Kim HS, Kacew S and Lee BM, In Vitro Chemo- preventive Effects of Plant Polysacchrides (Aloe barba- densis Miller, Lentinus edodes, Ganoderma lucidum, and Coriolus vesicolor). Carcinogenesis. 1999; 20(8):1637-1640.

45. Ishii $\mathrm{Y}$, Tanizawa $\mathrm{H}$ and Takino $\mathrm{Y}$, Studies of Aloe. V. Mechanism of Cathartic Effect. (4). Biological \& Phar-maceutical Bulletin 1994; 17(5):651-653.

46. Zawahry ME, Hegazy MR and Helal M, Use of Aloe in Treating Leg Ulcers and Dermatoses. Interna- tional Journal of Dermatology. 1973; 12(1):68-73

47. Saroj PL, Dhandar DG and Singh RS, Indian Aloe. Central Institute for Arid Horticulture. Bikaner, 2004

48. S. Foster, Aloe vera: The Succulent with Skin Soothing Cell Protecting Properties. Herbs for Health Magazine, 1999.

49. M. Castleman, The Healing Herbs. Rodale Press, Em-maus. 1991; 42-44.

50. Simon PW, Domestication, Historical Development and Modern Breeding Carrot. Plant Breeding Reviews. 2000; (19):157-190.

51. Dias JS, Nutritional Quality and Health Benefits of Vegetables. A Review. Food and Nutrition Sciences. 2012; (3):1354-1374

52. Dias JS, Major Classes of Phytonutriceuticals in Vegetables and Health Benefits. A Review. Journal of Nutritional Therapeutic. $2012 ; 1: 31-62$

53. Matsunaga $\mathrm{H}$, Katano $\mathrm{M}$, Yamanoto $\mathrm{H}$, Fujito $\mathrm{H}$ and Takata MM, Cytotoxic Activity of Polyacetylene Compounds in Panax ginseng C.A Meyer. Chemical and Pharmaceutical Bulletin. 1990 (38):3480-3482

54. Saita T, Katona M, Matsunaga H, Yamamsoto H, Fujito H. and Mori M, The First Specific Antibody against Cytotoxic Polyacetylenic Alcohol, Panaxysol. Chemical and Pharmaceutical Bulletin. 1993; (41):549-552

55. Coyne T, Ibiebele TI, Baade, PD., Dobson, A, McClintock, C, Dunn, S., Leonard, D. and Shaw, J. 2005. Diabetes Mellitus and Serum Carotenoids: Finding of a Population-Based Study in Queensland Australia. The American Journal of Clinical Nutrition. 2005; (82):685-693.

56. Nicolle C, Cardinault N, Aprikian O, Busserolles J, Grolier P, Rock E, Demigne C, Mazur A, Scalbert A, Amouroux P and Remesy, C Effect of Intake on Cholesterol and on Antioxidant Status in Cholesterol-Fed Rat'. European Journal of Nutrtion. 2003; (42): 254-261

57. Bishayee A, Sarkar A and Chatterjee M. Hepatoprotective Activity of Carrot (Daucus carota L.) against Carbon Tetrachloride Intoxication in Mouse Liver. Journal of Ethnopharmacology. 1995; 1(47):69-74

58. Patil, MV, Kandhare, AD. and Bhise, SD.Pharmacological Evaluation of Extract of Daucus carota Linn Root Formulated Cream on Wound Healing Using Excision and Incision Wound Model. Asian pacific Journal of Tropical Biomedicine, 2012; (2):S646-S655.

59. Adom KK, Liu RH, Antioxidant Activity of Grains. J Agri Food Chem. 50:6182-6187.

60. C,f. Health Foods'. Concept, Technology and Scope by Gupta, R.K., Bansal, Sangita, Mangal, Manisha Vol I pp. 294-295. Biotech Publishing House, New Delhi.

61. Ebrahimzadeh M. A, Pourmorad F, Hafezi S. Antioxidant Activities of Iranian Corn Silk. Turk J Biol. 2008; 32(1):43-49.

62. El-Ghorab A, El-Massry K F, Shibamoto T. Chemical Composition of the Volatile Extract and Antioxidant Activities of the Volatile and Nonvolatile Extracts of Egyptian Corn Silk (Zea mays L.). J Agric Food Chem. 2007; 55(22):9124-27.

63. Habtemariam S. Extract of Corn Silk (Stigma of Zea mays) Inhibits the Tumour Necrosis Factor-alpha-and Bacterial Lipopolysaccharide-induced Cell Adhesion and ICAM-1 Expression. Planta Med. 1998; 64(4):314-318

64. Wang G-Q, Xu T, Bu X-M, Liu B-Y. Anti-inflammatory Effects of Corn Silk in a Rat Model Carrageenin-induced Pleurisy. Inflammation. 2012; 35(3):822-827.

65. Hu QL, Zhang LJ, Li YN, Ding YJ, Li FL. Purification and Antifatigue Activity of Flavonoids from Corn Silk. Int. J. Phys. Sci. 2010(5): 321-326

66. Sepehri G, Derakhshanafar A, Yazdi Zadeh F. Protective Effects of Corns Silk Extract Administration on Gentamacin-induced Nephrotoxicity in Rat. Comp Clin Pathol. 2011; 20(1):89-94. 